\title{
Corneal endothelial changes in correlation with corneal thickness after phacoemulsification among diabetic patients
}

\begin{abstract}
Purpose: We proposed to study the corneal endothelial change in correlation with corneal thickness after phacoemulsification with Intra Ocular Lens IOL implantation; comparing diabetics (long standing $>10$ years) versus a control group of non-diabetics. These cataract patients were obtained from the Ophthalmology Clinic at Suez Canal University Hospital, Ismailia, Egypt.
\end{abstract}

\begin{abstract}
Aim: To determine how corneal endothelium in diabetic patients is affected by cataract surgery in comparison to age matched non-diabetics. This assessment will be made over the initial 1 month post-op period and will be determined (evaluated) by specular microscopy (model Nidek CEM 5301) as a primary report (Figure 1).
\end{abstract}

Conclusion: Corneal endothelium in diabetic patients is more affected during the phacoemulsification for cataract extraction \& IOL implantation surgery as evidenced in (one week) follow up post op. Comparison between pre-operative and post-operative (one month) photo-analysis versus control cataracts in non-diabetic patients of similar age group revealed significant difference in central corneal thickness CCT and hexagonal cell count due to delayed endothelial recovery. No significant difference in endothelial cell density (Table 1).

Keywords: corneal endothelium, corneal thickness, phacoemulsification, diabetic patients
Volume 7 Issue I - 2017

Osama Elbassiouny, Ali Khalil, Osama Al
Nahrawy, Ahmed Rashid
Ophthalmology Department, Suez Canal University, Egypt

Correspondence: Osama Elbassiouny, Professor \& Founding Director of Ophthalmology Department, Senior Consultant Ophthalmic Surgeon, Suez Canal University Hospital, FOM, SCU, Ismailia, Egypt, Email osama.elbassiouny@med.suez.edu.eg

Received: May 20, 2017 | Published: May 30, 2017

\section{Methods}

We prospectively examined 23 eyes of each group of patients who were scheduled to have phacoemulsification surgery. Materials were collected from December 2016 till April 2017. Exclusion criteria were a history of previous ocular surgery or inflammation, abnormal findings by slit-lamp biomicroscopic examination, a small pupil diameter after a full dilation of less than $4.0 \mathrm{~mm}$, and a preoperative endothelial cell density of less than 1500 cells $/ \mathrm{mm} 2$. One surgeon performed all the surgeries. Specular microscopy was used on all eyes preoperatively, one week and one month postoperatively. Three photographs were taken per eye at each examination, and the mean of the measurements were calculated. The CCT (central corneal thickness), ECD (endothelial cell density), and CV (coefficient of variance) will be measured in all cases by automated analysis of the whole image. Complete medical history for type 2 diabetes based on medical history, blood glucose levels and $\mathrm{HbAlc}$ levels. Examination of visual acuity, subjective refraction, slit-lamp examination, IOP readings with applanation tonometry was done to all patients. Binocular indirect ophthalmoscopy was conducted for fundus examination.

The density of the cataract was clinically graded by the same examiner on a scale of 1 to 6 using the Lens Opacities Classification system 11l. IOL power and AC depth were recorded for all patients. A standardized stop and chop phacoemulsification technique was done with the phaco tip of 'white star Signature Pro ${ }^{\circledR}$ ' Phaco-machine. Surgical techniques were conducted using retrobulbar anesthesia.
Clear corneal incision was used with a $3.2 \mathrm{~mm}$ keratome. Sodium hyaluronate was injected to maintain the depth of the anterior chamber. Capsulorhexis completed using fine forceps. Hydro dissection was performed and the lens nucleus emulsified with Phaco machine using the stop and chop technique. The power used was $40-60 \%$, a vacuum of $60-350 \mathrm{mmHg}$, and an aspiration flow rate of $25-30 \mathrm{ml} / \mathrm{min}$. The bottle height raised to a maximum of $110 \mathrm{~cm}$ from a minimum of 90 $\mathrm{cm}$ during fragment removal.

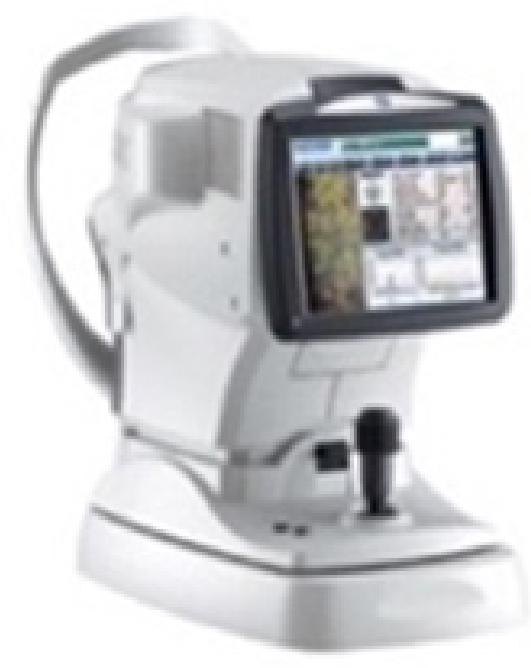

Figure I Nidek CEM530I. 
Table I Corneal parameters among the 2 study groups and across the 3 assessment points

\begin{tabular}{|c|c|c|c|c|}
\hline Parameter & & $\begin{array}{l}\text { Non-diabetics } \\
\text { (mean } \pm S D)\end{array}$ & $\begin{array}{l}\text { diabetics } \\
\text { (mean } \pm S D)\end{array}$ & $p$-value \\
\hline \multirow{4}{*}{$\begin{array}{l}\text { Endothelial } \\
\text { cell density }\left(\text { cells } / \mathrm{mm}^{2}\right) \\
\text { ECD }\end{array}$} & Preoperative & $2502.9 \pm 232.2$ & $24|0.3 \pm 30| .2$ & $0.249^{\prime}$ \\
\hline & I week postop. & $2062.8 \pm 410.3$ & $1869.6 \pm 411.9$ & $0.087^{2}$ \\
\hline & I Month postop. & $2045.8 \pm 47$ I.I & $1810.3+401.9$ & 0.075 \\
\hline & $p$-value & $<0.001^{3 *}$ & $<0.001^{3 *}$ & \\
\hline \multirow{4}{*}{$\begin{array}{l}\text { Coefficient of Variation (\%) } \\
\text { CV }\end{array}$} & Preoperative & $29.3 \pm 4.4$ & $32.3 \pm 6.2$ & $0.066^{\prime}$ \\
\hline & I week postop. & $35.5+8.2$ & $40.5+6.6$ & 0.027 \\
\hline & I Month postop. & $30.8+4.9$ & $37.2+6.2$ & $<0.0001$ \\
\hline & $p$-value & $<0.001^{3 *}$ & $<0.001^{3 *}$ & \\
\hline \multirow{4}{*}{ SD(um2) } & Preoperative & $110.6 \pm 17$ & $126.9 \pm 31.6$ & $0.035^{1 *}$ \\
\hline & I week postop. & $177.9 \pm 97$ & $204.2 \pm 78.2$ & $0.034^{2 *}$ \\
\hline & I Month postop. & $159.2 \pm 67.1$ & $183.8 \pm 56$ & $0.020^{2 *}$ \\
\hline & $p$-value & $<0.001^{3 *}$ & $<0.00 \mathrm{I}^{3 *}$ & \\
\hline \multirow{4}{*}{$\begin{array}{l}\text { Central Corneal Thickness } \\
\text { (um) } \\
\text { CCT }\end{array}$} & Preoperative & $528 \pm 35.5$ & $532.3 \pm 33.9$ & $0.679^{\prime}$ \\
\hline & I week postop. & $543.6 \pm 43.9$ & $567.6 \pm 40.9$ & $0.062^{\prime}$ \\
\hline & I Month postop. & $531.7 \pm 35.1$ & $547.1 \pm 33.7$ & $0.124^{\prime}$ \\
\hline & $p$-value & $<0.001^{3 *}$ & $<0.001^{3 *}$ & \\
\hline \multirow{4}{*}{ Hexagonal cell } & Preoperative & $69.7 \pm 4.2$ & $68.8 \pm 5.5$ & $0.55 \mathrm{I}^{\prime}$ \\
\hline & I week postop. & $62.9 \pm 8.4$ & $55.3 \pm 8.9$ & $0.003^{2 *}$ \\
\hline & I Month postop. & $65.4 \pm 8.8$ & $61.9 \pm 7.1$ & $0.028^{2 *}$ \\
\hline & $p$-value & $<0.001^{3 *}$ & $<0.001^{3 *}$ & \\
\hline
\end{tabular}

I. Student's $t$ test; 2. Mann Whitney $U$ test;

3. Friedman test; $*$ Statistically significant at $p<0.05$

Care was taken to perform phacoemulsification at the posterior plane. Bimanual irrigation/aspiration was performed for cortex removal. After expanding the capsular bag with Healon, a foldable hydrophilic acrylic intraocular lens (Slim fold, $6 \mathrm{~mm}$ optic, $13 \mathrm{~mm}$ overall diameter with preloaded injector) was implanted in the bag. Removal of the residual viscoelastic with bimanual irrigation/ aspiration, then hydration of the wound edges to seal the incisions. The fluid volume used (from commencement of sculpting to the end of viscoelastic removal after IOL implantation) and the effective phaco time (average ultrasound power $\times$ average ultrasound time/100) was noted for each case. The postoperative regime was standardized in all groups (prednisolone $1 \%$ \& moxifloxacin $0.5 \%$ eye drops $\mathrm{X} 5$ daily with non-steroidal anti-inflammatory eye drops X 3 daily. Tobradex eye ointment used at bed time) include reducing rate for 4 weeks.

\section{Results}

Forty-six patients with cataract were enrolled in the study; 23 were diabetics and 23 were non-diabetics. Mean age of study participants are shown in (Table 2-4).

Table 2 Mean of study participants

\begin{tabular}{llll}
\hline Age & $\begin{array}{l}\text { Non-diabetics } \\
\text { no (\%) }\end{array}$ & $\begin{array}{l}\text { Diabetics } \\
\text { no. }(\%)\end{array}$ & p-value \\
\hline Mean \pm SD & $58.9 \pm 7.4$ & $60.3 \pm 6.1$ & $0.508^{\prime}$ \\
Median (range) & $59(44-70)$ & $60(50-70)$ & \\
\hline
\end{tabular}

I. Mann Whitney U test 
Table 3 Diabetic history among diabetic group $(n=23)$

\begin{tabular}{|c|c|c|c|c|}
\hline & & & Frequency & $\%$ \\
\hline \multirow{4}{*}{ DM duration } & \multicolumn{2}{|l|}{$10-15$} & 12 & $52.2 \%$ \\
\hline & \multicolumn{2}{|c|}{$>15-20$} & 10 & $43.5 \%$ \\
\hline & \multicolumn{2}{|l|}{$>2$} & I & $4.3 \%$ \\
\hline & \multicolumn{2}{|c|}{ Mean $\pm S D$} & $15.9 \pm 4.3$ & \\
\hline \multirow{2}{*}{ TTT of DM } & \multicolumn{2}{|l|}{ Insulin } & 11 & $47.8 \%$ \\
\hline & \multicolumn{2}{|c|}{ Oral hypoglycemic } & 12 & $52.2 \%$ \\
\hline \multirow{5}{*}{ Diabetic Retinopathy } & \multirow{3}{*}{ NPDR } & Mild & 11 & $47.8 \%$ \\
\hline & & Moderate & 8 & $34.8 \%$ \\
\hline & & Severe & 2 & $8.7 \%$ \\
\hline & \multirow{2}{*}{ PDR } & Low risk & I & $4.3 \%$ \\
\hline & & High risk & I & $4.3 \%$ \\
\hline
\end{tabular}

Table 4 Blood sugar assessment among the two study groups

\begin{tabular}{llll} 
Blood sugar assessment & $\begin{array}{l}\text { Non-diabetics } \\
(\mathbf{m e a n} \pm \mathbf{S D})\end{array}$ & $\begin{array}{l}\text { Diabetics } \\
(\mathbf{m e a n} \pm \mathbf{S D})\end{array}$ & p-value \\
\hline RBS & $120.2 \pm 17.9$ & $224.1 \pm 73.1$ & $<0.0011^{*}$ \\
FBS & $90.3 \pm 9.8$ & $147.3 \pm 50.2$ & $<0.0011^{*}$ \\
HBAIc & $4.2 \pm 0.72$ & $8.5 \pm 1.2$ & $<0.0011^{*}$
\end{tabular}

Mann Whitney $U$ test; *Statistically significant at $p<0.05$

\section{Discussion}

The international Diabetes Federation 'IDF' has listed Egypt as one of the top 10 countries in the world with diabetes. ${ }^{1}$ Hegazi et al. ${ }^{2}$ studied epidemiology and risk factors for Type 2 Diabetes in Egypt. In our study a non-contact specular microscope and optical pachymeter model Nidek CEM-5301 is being adopted. It is intended for studying the corneal endothelium and measuring the corneal thickness, with a capture field of $0.25 * 0.55 \mathrm{~mm}$ providing a wide field highly magnified image. It is provided with one central fixation lamp, 8 para-central fixation lamps, and 6 peripheral fixation lamps (Figure 2,3). Multiple photos that are captured are analyzed within seconds, automated analysis include different parameters of endothelial structure and two detailed graphic and color coded analysis including area graph for plotting polymegathism and apex graph for plotting pleomorphism. The device can offer advanced manual analysis and combined manual automated analysis to specifically select abnormal cells or to manually analyze photos using different methods either center point, corner point or pattern select or automated photo, trace, area and apex mode analysis (Figure 4).

Many kinds of surgical trauma during phacoemulsification have been reported to injure corneal endothelial cells. ${ }^{3}$ Some studies demonstrate that ultrasound energy and irrigation directly injure the endothelium. ${ }^{4,5}$ Others emphasize that traumatic endothelial contact with nuclear fragments, IOL, air bubbles and surgical instruments are the principal causes of endothelial injury. ${ }^{6}$ The clarity of the cornea is due to its relative deturgescence related to several anatomical, physiological and physical factors. ${ }^{7}$ The cornea is avascular giving it transparency, its central part is supplied with oxygen, nutrients by the tear film and aqueous while the corneo-scleral part is supplied from the anterior conjunctival branches of the anterior ciliary arteries. It is innervated by non-myelinated sensory nerve fibers arising from the long ciliary nerves of the nasociliary nerve of the ophthalmic nerve arising from the trigeminal nerve. ${ }^{8}$ It is responsible for maintaining the corneal deturgescence through two important mechanisms. ${ }^{9}$ The active transport pump system (ATPase pump sites at the base-lateral membranes) and the intracellular carbonic anhydrase pathway (the passive i.e. leak).

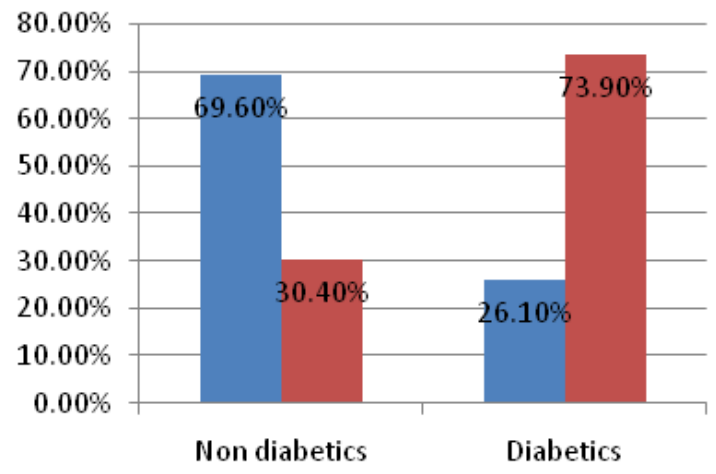

$p=$ 0.003

Male

- Female

Figure 2 gender distribution of participants. 

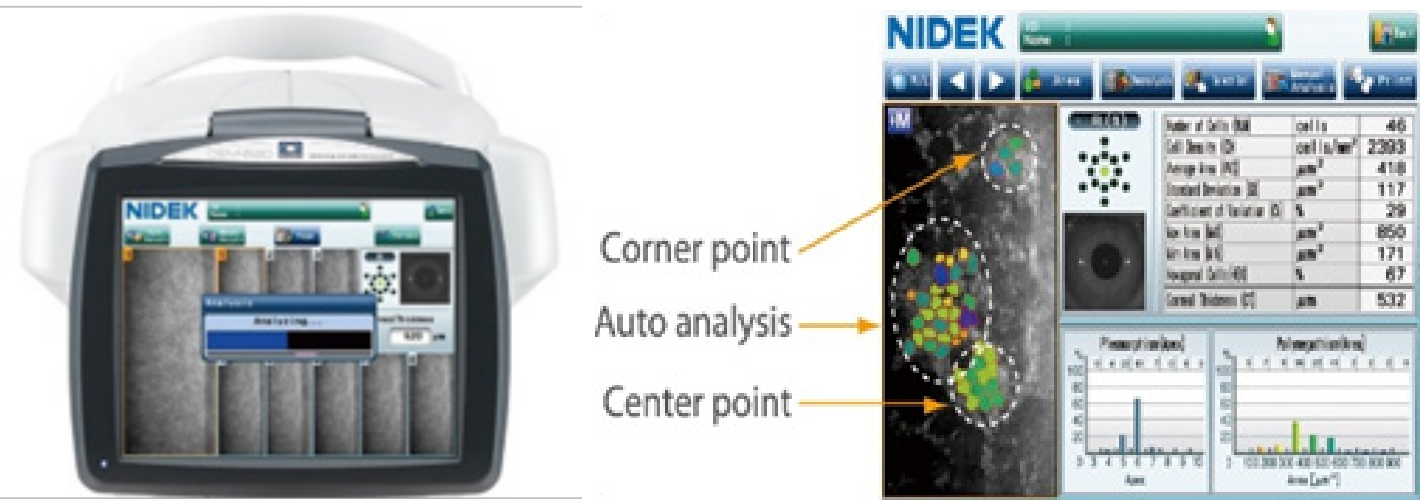

Figure 3 Screen Display used in our study analysis.

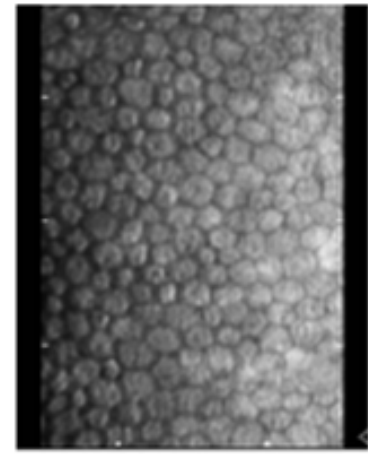

Good Quality

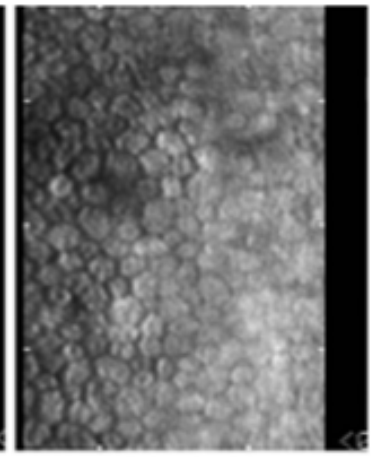

Fair Quality

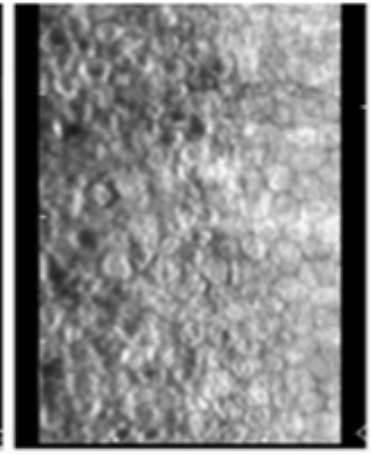

Poor Quality

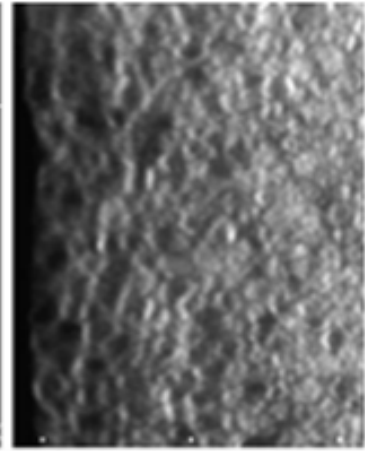

Impossible Quality

Figure 4 Endothelial cells counted in a 2500 cells/mm2 cornea vs image quality.

Age can cause changes in corneal endothelial cells. ${ }^{10}$ Presence of DM can cause persistent corneal defects, recurrent corneal erosions, punctate epithelial keratopathy and endothelial abnormalities including decrease in endothelial cell density (CD) and hexagonality, as well as increased polymegathism, polymorphism, and central corneal thickness (CCT). There was relationship found between ECD, CCT and severity of diabetes mellitus, the CCT was statistically significant among diabetics especially those with proliferative diabetic retinopathy 'PDR' making thick corneas in diabetic patients an indicator for risk of retinal complications. ${ }^{11}$ The specular microscopy when first invented was of the contact type a technique implies applanation of cornea with a dipping cone mounted on the outside of a microscope objective. The applanation is of help in keeping the endothelial cells in focus and allows a high magnification (about 200x). This contact type has two main disadvantages the small area of visualization at time of examination and the corneal contact as it requires topical anesthesia before applanation which carries risk of traumatizing the anterior corneal surface or even infection transmission, and even more difficult examination if the cornea has opacities. $^{12}$

In recent developments non-contact, specular microscope, ${ }^{13}$ the Light from a 6-V viewing lamp was passed through a slit aperture and condensing lens. The slit beam was directed by a system of mirrors out through the objective lens of the microscope and into the cornea. The objective was a $20 \mathrm{X}$ water immersion lens with a flatsurfaced glass dipping cone extension that applanated the cornea, as in placing an applanation tonometer on the eye. The dipping cone may be adjusted by turning a knob to focus the image at different corneal thicknesses. The Zeiss viewing lamp was focused in the same plane as a xenon flash tube, which allowed clear photographs to be taken despite continuous small eye movements. Topically applied anesthetic was applied to the cornea before the examination.

The endothelial cell density analysis can be performed by the comparison method, frame method (fixed or variable), corner method, and center-to-center method. Image quality is important determinant of analysis accuracy. The comparison method provides a subjective cell density value by a comparing the patient's endothelial cell pattern to a known set of hexagon patterns for various cell densities. This method is typically performed while viewing the patient's endothelium or from the hexagon patterns included on the cell image window. The frame method provides a numerical assessment of the cell density by counting the number of cells within a frame. To adjust for cells extending outside the frame, one counts partial cells extending over 2 adjacent frame borders as full cells. The corner method is performed with a photograph print. The intersecting cell sides are located and inputted into a digital pad to define the area of the cell polygon. Computer programs are used to calculate the endothelial cell morphology parameters of cell area and number of sides per cell. The corner method accuracy is determined by a subjective decision of defining the cell borders and applying the appropriate image magnification. ${ }^{14}$

The center-to-center method is the technique used with the specular microscope. It is a quicker data entry method and easier to approximate the center of the cells than determining the intersecting cell borders. The computer mouse or the touch screen is used to dot the center of the captured specular microscope digital cell image. The 
endothelial cell morphology parameters of cell area and number of sides per cell are calculated. The error rate can range from $0.5 \%$ to $5.0 \%$. The corner method and the center method have been reported in other studies to be equivalent. The accuracy will depend greatly on the skillfulness of the technician performing the analysis. The centerto-center method accuracy is determined by a subjective decision to define a cell, omitting cell(s), double entering cells, centering the dot in the cell, and image magnification. Placing the dot off center in the cell will have minimal effect on determining the cell area. A simple test was performed to assess the effect of off-centering the dots. Offcentered dots will increase mean cell area SD but have little effect on mean cell area value, which is used to calculate cell density. The effect of omitting cells during analysis was evaluated by progressively omitting up to 10 hexagons randomly spaced in the field. The percent errors from omitting hexagons were $1.0 \% \pm 0.1 \%$ per hexagon omitted for 1700 hexagons $/ \mathrm{mm} 2$ and $0.6 \% \pm 0.1 \%$ per hexagon omitted for 2500 hexagons $/ \mathrm{mm} 2$. The error in determining cell density from omitting cells in the analysis field was linear. If 5 hexagons were omitted per field, the total error would be $5.0 \%$ for the 1700 density and $3.0 \%$ for the 2500 density.

Picking up cells in specular microscope capture frame can be difficult. The cell border is determined by shadows in the image. The shadows can be incomplete around the cell or extend across the center of the cell. In each case, the subjective decision requires experience by the reader to be performed with consistency. Poor recognition of the cell borders can result in errors of omitting cells or double entering cells during the analysis. For each cell omitted from a 100cell analysis field, there will be a $1 \%$ reduction in the calculated cell density for an endothelial cell pattern of 2500 cells $/ \mathrm{mm} 2$. The error estimate is affected by the number of cells counted and cell density. For cell densities of 2500 cells $/ \mathrm{mm} 2$, the error effect becomes greater. For each cell with an extra dot (i.e., double entered), there was a $1 \%$ $(0.6 \%-0.8 \%)$ increase in the calculated cell density for an endothelial cell pattern of 2500 cells $/ \mathrm{mm} 2$. Once again, this result is affected by the number of cells counted and cell density. Many researchers have suggested guidelines for maximum accuracy of specular microscope analysis. Binder et al. ${ }^{15}$ expanded the guideline by suggesting "as many cells in the image frame as possible, with 3 images per patient from the center and para central regions with the average analysis of all 3 images to give estimated cell density count".

The non-contact specular microscope can capture 120-170 cells per image. The actual number of cells per image depends on the endothelial cell density, the smaller the endothelial cell density, the fewer the number of cells maximally analyzed per capture field, and the higher the endothelial cell density, the larger the number of cells analyzed per capture field for e.g. A cornea with a cell density of 2500 cells $/ \mathrm{mm} 2$ has 118 cells in the field. Thus, 120 is the maximum number of cells that can be counted from 1 sample field. A cornea with a cell density of $1500 \mathrm{cell} / \mathrm{mm} 2$ had a maximum number of 65 cells. When the human corneal endothelium is damaged, ${ }^{16}$ the healing is a process of cellular enlargement and spreading to create a contiguous layer of cells on the inner surface of the cornea. The degree of endothelial cell loss from, for example, disease, trauma, or chemical toxicity can be documented with specular microscopy as an increase in individual cell surface area and a decrease in the endothelial cell density for the cornea. The corneal endothelial cell wound repair is also reflected as an increase in the variation of individual cell areas, i.e., polymegathism or coefficient of variation (CV). Six-sided cells are an indication of an even distribution of membrane surface tension and of normal cells.

Abnormal corneal endothelium pleomorphism indicates drop in the hexagonality of cells below $50 \%$, resulting in disruption in the normal endothelial mosaic pattern due to different traumatic or stress factors, this disruption may affect the endothelial barrier effect and its normal pump function. So, the patient is considered to have clinically significant pleomorphism when hexagonality of cells is less than $50 \%$ putting the patient at risk of developing post-operative corneal decompensation or endotheliopathies. Polymegathism indicates an elevated mean cell area which is usually the first sign of endothelial disease. This finding denotes physiological stress to the corneal endothelium and an overactive post-operative wound repair mechanism. CV values from 0.32 to 0.40 are elevated, and $C V$ values above 0.40 are abnormal. Although endothelial function may still be intactin these corneas, the endothelium may be more susceptible to additional trauma from insults, such as intraocular surgery, glaucoma, diabetes, uveitis or contact lens wear.

Longstanding hyperglycemia has direct inhibiting effect on corneal endothelial active pump function. The corneal endothelium became a vulnerable layer in response to phacoemulsification surgery. In our study, we found differences in CCT, higher SD and less ECD in diabetic group compared to control group due to delayed recovery of endothelial cell function in response to surgical procedure. We recommend much care has to taken to corneal endothelium during our cataract procedure with IOL implantation by using low phaco parameters \& coating techniques.

\section{Acknowledgments}

None.

\section{Conflicts of interest}

The authors declare no conflicts of interest.

\section{References}

1. Egypt. International Diabetes Federation. $7^{\text {th }}$ edn. 2015.

2. Hegazi R, El-Gamal M, Abdel-Hady N, et al. Epidemiology of and Risk Factors for Type 2 Diabetes in Egypt". Ann Glob Health. 2015;81(6):814 820.

3. Hyndiuk RA, Schultz RO. Overview of the corneal toxicity of surgical solutions and drugs: and clinical concepts in corneal edema. Lens Eye Toxic Res. 1992;9(3-4):331-350.

4. Hayashi K, Hayashi H, Nakao F, et al. Risk factors for corneal endothelial injury during phacoemulsification. $J$ Cataract Refract Surg. 1996;22(8):1079-1084.

5. Bourne RR, Minassian DC, Dart JK, et al. Effect of cataract surgery on the corneal endothelium: Modern phacoemulsification compared with extracapsular cataract surgery. Ophthalmology. 2004;111(4):679-685.

6. Bonanno JA. Molecular mechanisms underlying the corneal endothelial pump. Exp Eye Res. 2012;95(1):2-7.

7. Devgan U. Phaco fluidics and phaco ultrasound power modulations. Ophthalmol Clin North Am. 19(4): 457-468.

8. Oliveira-Soto L, Efron N (2001) Morphology of Corneal Nerves Using Confocal Microscopy. Cornea. 2006;20(4):374-384. 
9. Vasavada AR, Praveen MR, Vasavada VA, et al. Impact of high and low aspiration parameters on postoperative outcomes of phacoemulsification: Randomized clinical trial. J Cataract Refract Surg. 2010;36(4):588-593.

10. Yee RW, Matsuda M, Schultz RO, et al. Changes in the normal corneal endothelial cellular pattern as a function of age. Curr Eye Res. 1985;4(6):671-678.

11. Shukla E, Nicholson A, Agrawal A, et al. Correlation between severity of Type 2 diabetes mellitus and corneal morphology using specular microscopy in Indian population: A case-control study. Sudan J Ophthalmol. 2016;8(1):30--35.

12. Bourne WM, Kaufman HE. Specular Microscopy of Human Corneal Endothelium in VIVO. Am J Ophthalmol. 1976;81(3):319-323.
13. Olsen T. Non-Contact Specular Microscopy of human corneal endothelium. Acta Ophthalmol. 2009;57(6):986-998.

14. McCarey BE, Edelhauser HF, Lynn MJ. Review of corneal endothelial specular microscopy for fda clinical trials of refractive procedures, surgical devices, and new intraocular drugs and solutions. Cornea. 2008;27(1):1-16.

15. Binder PS, Sternberg H, Wickham MG, et al. Corneal Endothelial Damage Associated by Phacoemulsification. Am J Ophthalmol. 1976;82(1):48-54.

16. Inaba M, Matsuda M, Shiozaki Y, et al. Regional specular microscopy of endothelial cell loss after intracapsular cataract extraction: A preliminary report. Acta Ophthalmol. 2009;63(2):232-235. 